
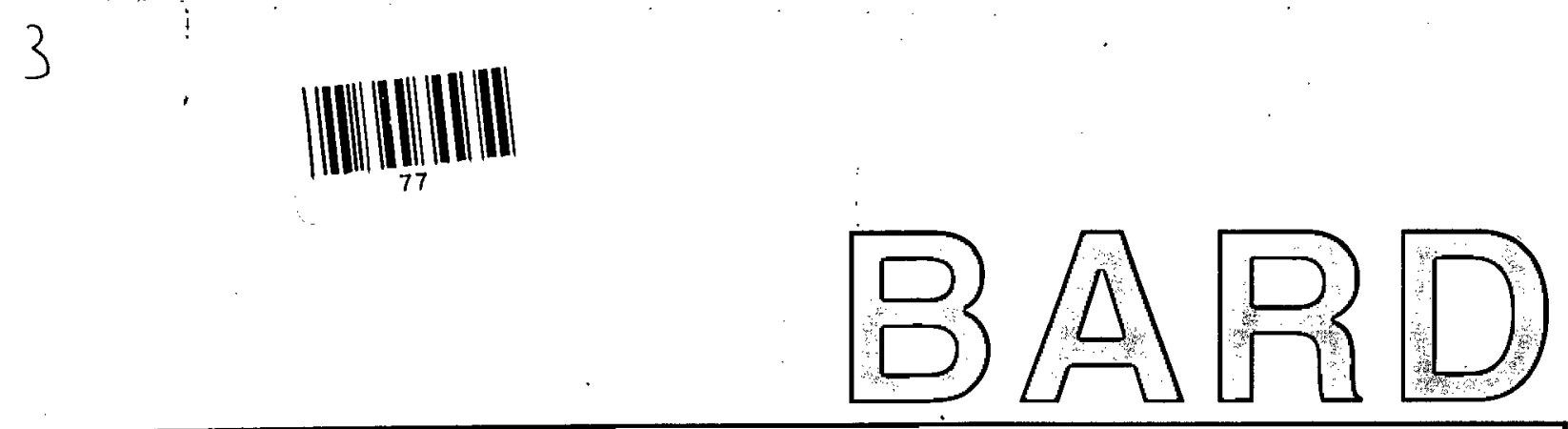

FINAL REPORT

$\rightarrow \quad$ PROJECT NO. IS-2128-92

Induction of Resistance to Postharvest Diseases and Extension of Shelf-Life of Fruits and Vegetables by Ultraviolet Light

E. Chalutz, S. Droby, V. Gaba, R. Fluhr, C. Wilson, C. Stevens, Y. Lu 
Date: May 15, 1997

Bard project No. IS-2128-92C

Project Title: Induction of Resistance to Postharvest Diseases and Extension of Shelf-life of Fruits and Vegetables by Ultra-violet Light.

Investigators' Names

(Principal listed first)
E. Chalutz
S. Droby
V. Gaba
R. Fluhr
C. Wilson
C. Stevens
Y. Lu

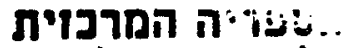
למדעי החקלאות ביח-תון

\section{Investigators' Institutions}

ARO, The Volcani Center, Israel ARO, The Volcani Center, Israel ARO, The Volcani Center, Israel The Weizmann Institute, Israel USDA, Kearneysville WV, USA Tuskegee University AL, USA Tuskegee University AL, USA

Project starting date: February 15, 1994

Type of Report: 1st Annual _ 2nd Annual _ Final X

\section{E. Chabuty}

Signature

Principal Investigator

630.72
BARlato
dat $\mathrm{cm}$

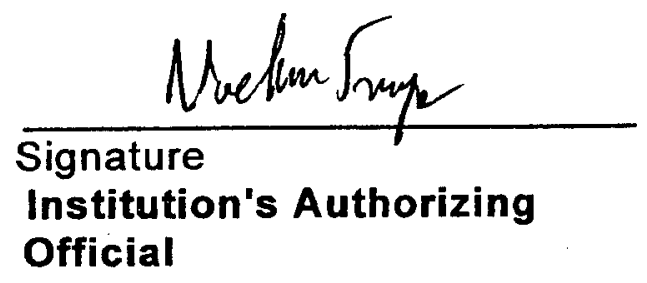


Evaluation of research achievements 


\title{
Induction of Resistance to Postharvest Diseases and Extension of Shelf-life of Fruits and Vegetables by Ultra-violet Light.
}

\begin{abstract}
Following preliminary observations by one of the collaborating scientists on this project and the completion of a 1-year, BARD-supported feasibility study (IS-1908-90F), this 3-year BARD project has been executed. The main objectives of the research were to elucidate biochemical and pathological aspects of UV-induced resistance in fruits and vegetables; to characterize physical and biological variables of induced resistance and delay of ripening, and to explore the application of the treatment as a control practice of postharvest diseases and shelf-life extension of fruits and vegetables.

Our findings, which are detailed in numerous joint publications, have shown that the effect of UV-C light on induction of resistance and delay of ripening is a general one and of wide occurrence. Apart from surface sterilization of the commodity, the reduction of decay of different fungi has been associated with an induced resistance phenomenon which gradually builds up within 24 to 48 hours after the UV treatment and can be reversed by visible light. In citrus, induced resistance has been associated with increased activity of the enzymes phenylalanine ammonia-lyase and peroxidase, and with the levels of endoglucanase and chitinase. In tomato, resistance was correlated with the production of high levels of tomatine.

Our study of some molecular aspects of the induced resistance in grapefruit has revealed the induction of a cDNA which represents a gene encoding for an isoflavone reductase-like protein that, in legumes, has been associated with phytoalexin biosynthesis. This gene was cloned and sequenced.

Delay of ripening was associated in tomato with inhibition of ethylene production, carotenoid synthesis, and chlorophyll degradation and with the presence of high levels of polyamines. In peach fruit epiphytic populations of a yeast increased following the UV treatment.

Pilot-size treatment and packing lines were constructed in the US and Israel to test the application of the UV treatment on a semi-commercial scale. Although effective in reduction of decay and delay of ripening, a number of problems will have to be addressed before practical application of this methodology can be realized. The main issues are associated with the temporal and variable response to the treatment, and its relationship to the maturity and date of harvest of the commodity.
\end{abstract}




\section{Objectives of original research proposal}

The following are the stated objectives of the original proposal:

1. Elucidate biochemical and pathological aspects of the UV-induced resistance in fruits and vegetables.

2. Characterize physical and biological variables of induced resistance and delay of ripening and explore the application of the treatment as a control practice for postharvest diseases and shelf-life extension of fruits and vegetables.

\section{Relevant data, methodology, results and discussion.}

(The work in Israel has been conducted in collaboration with $L$. Cohen, B. Weiss, A. Daus, and B. Horev).

As outlined in our two Annual Reports, the research has elucidated biochemical and pathological aspects of the UV-C induced resistance, as well as biological and physical variables that affect the response of the tissue of several fruits and vegetables. In addition, at two collaborating laboratories - the USDA laboratory in West Virginia and the ARO laboratory at the Volcani Center - pilot plants have been built which enabled the exploration of the on-line application of the methodology on a semi-commercial scale with different fruits.

Our findings have been summarized in numerous joint manuscripts. Most have already been published in scientific journals and their reprints are included herewith as part of this report. Others, not yet published, are included as submitted manuscripts. Still other publications are included and cited in the List of Publications. The list (including those publications originating from a preceding 1-year, BARD-supported feasibility study) contains 7 publications in reviewed journals, 5 manuscripts which have been or are about to be submitted to reviewed journals, and 13 other publications. 
The relevant methodology, data, and discussion is divided into three major parts: (1) Physical and biological variables of induced resistance and delay of ripening; (2) Biochemical and pathological aspects of the UV-induced resistance; and (3) Application of the UV treatment. In each of these parts, the relevant publications are listed first followed by a brief summary of their content. The full manuscripts are enclosed at the end of the written text in the order of their referral in the test of the report. The publication number refers to its location on the "List of Publication".

\section{Physical and Biological Variables of Induced Resistance and Delay of Ripening}

Physical and biological variables have been studied with several commodities: The early work with citrus fruit is described and discussed in the following two publications:

\#1. UV-induced resistance to postharvest diseases of citrus fruits. (Chalutz, et al., 1992).

\#2. Factors affecting UV-induced resistance in grapefruit against the green mould decay caused by Penicillium digitatum. (Droby, et al., 1993).

Our data has shown clearly that reduction of decay following the UV treatment is not merely a surface sterilization phenomenon but rather is associated with induced resistance which builds up gradually within 24 to 48 hours after the treatment. The data also suggested that the inhibition of decay may be associated with the accumulation of fungal inhibitory substance(s) in the fruit peel that prevented or restricted fungal growth. Increase of activity of phenylalanine ammonia-lyase (PAL) and peroxidase correlated with the increase in resistance. (\#1).

Further characterization of this phenomenon has shown that grapefruit picked at various times during the harvest season responded differently to the UV 
treatment. The UV dose required for development of maximum resistance increased as the season progressed. Development of induced resistance was also depended on the storage temperature of the fruit during the initial 24 hours after the UV treatment. (\#2).

Other publications and manuscripts describing the work with sweet potato, tomatoes, and peach are the following:

\#15. Induced resistance response of sweet potato to Fusarium root rot by UV-hormesis. (Stevens, et al., 1992).

\#3. Application of Ultraviolet-C light on storage rots and ripening of tomatoes. (Liu, et al., 1993).

\#10. Application of hormetic UV-C for delayed ripening and reduction of Rhizopus soft rot in tomatoes: The effect of tomatine on storage rot development. (Stevens, et al., 1997).

\#4. Low dose UV and gamma radiation on storage rot and physicochemical changes in peaches. (Lu, et al., 1993).

\#9. The germicidal and hormetic effects of UV-C light on reducing brown rot disease and yeast microflora of peaches. (Stevens, et al., 1997).

The UV effect on induction of resistance has been demonstrated with sweet potatoes resistance against Fusarium solani. Increased PAL activity was associated with the phenomenon. Crude extracts from UV-treated sweet potato tissue reduced germination and germ-tube elongation and growth of $F$. solani. (\#15).

Similar results were obtained with resistance tomato against three major rot causing fungi - Alternaria alternata, Botrytis cinerea, and Rhizopus stolonifer. In addition, reduced rate of tomato ripening has been observed as shown by delayed softening and red color development. (\#3).

Our data with tomato has also shown that the UV-induced resistance to rot and delayed ripening was reversed by fluorescent light but not by storage under dark condition. Development of carotenoids, loss of chlorophyll and ethylene production were all inhibited during storage following the UV treatment. The 



\section{Biochemical and Pathological Aspects of the UV-Induced Resistance}

The biochemical aspects studied are summarized in the following two manuscripts:

\#11. Droby, S., Lars, a., Dori, S., Cohen, L., Wiess, B., Daus, A., Chalutz, E., Stevens, C., Wilson, C.L., and El Ghaouth, A. (1977).

Characterization of biochemical changes related to UV-induced resistance against green mold decay in grapefruit peel tissue.

Postharvest Biology \& Technology (to be submitted, included as part of this report).

\#12. Lars, A., Bord, S., Lomniec E., Droby, S. and Chalutz, E. (1977).

A grapefruit gene encoding an isoflavone reductase-like protein is activated in response to UV irradiation.

Plant Mol. Biol. (to be submitted, included as part of this report).

Two dimensional electrophoresis of the crude protein extract of UV-treated grapefruit peel suggested that the treatment affected the protein profile. It induced new proteins of approximately 65 and $409 \mathrm{kDa}$ and caused the disappearance of others. While no significant effect of UV on the enzyme level of endoglucanase was observed, levels of chitinase were affected. The combination of wounding and UV treatment affected the levels of both enzymes. (\#11).

In order to gain insight into the molecular basis of UV-induced resistance, we initiated a study aimed at identifying genes which are activated during this process. Using the differential display method, we cloned a cDNA representing an mRNA which is accumulated in grapefruit peel following the UV treatment. Sequence analysis revealed that this cDNA represents a gene encoding for an isoflavone reductase-like (IRL) protein that, in legumes, has been associated with phytoalexin biosynthesis. The protein sequence of the grapefruit IRL has high homology also to a novel family of proteins present in non-legume plants 
whose function is not clear yet. The optimum UV doses for induction of the IRL gene were 3.2 to $4.8 \mathrm{KJ} / \mathrm{m}^{2}$ which led to a maximal mRNA level after 24 hours corresponding to the optimal level for induction of resistance. The IRL gene was also induced by wounding and pathogen infection, thus supporting the possibility that it is involved in UV-induced resistance in grapefruit. (\#12).

\section{Application of the UV Treatment}

The following manuscript (accepted for publication) describes the pilot line and its use in this study.

\#7. An "on-line" UV-C apparatus to treat harvested fruit for the control of postharvest decay. (Wilson, et al., 1997).

Also included are pictures of the pilot lines at both the US and Israel locations.

An apparatus was designed to deliver low-dose UV-C light to the surface of fruit on a processing line and tested for the control of postharvest decay. It consisted of a row of UV-C emitting lamps mounted on a frame above a conveyer belt that transported the fruit. The dosage of the UV light delivered to the fruit surface was regulated by varying the speed of the conveyer belt. Postharvest decay after 28 days storage of 'Empire' apples was reduced $52 \%$ relative to the untreated checks when the fruit were conveyed at 6.2 meters per minute (1.38 $\mathrm{Kj} / \mathrm{M}^{2}$ dosage) under the UV apparatus. Factors affecting the practical application of UV-C irradiation of fruit for the control of postharvest decay are discussed. (\#7).

As shown on the following pictures, both pilot lines enabled the testing of the technology on a semi-commercial scale. The line in the United States (West Virginia) was used to test the effect of UV-C mostly with deciduous fruits and the one in Israel (shown on following page) mostly on citrus fruit. 
The on line application of the UV treatment in the USA General View
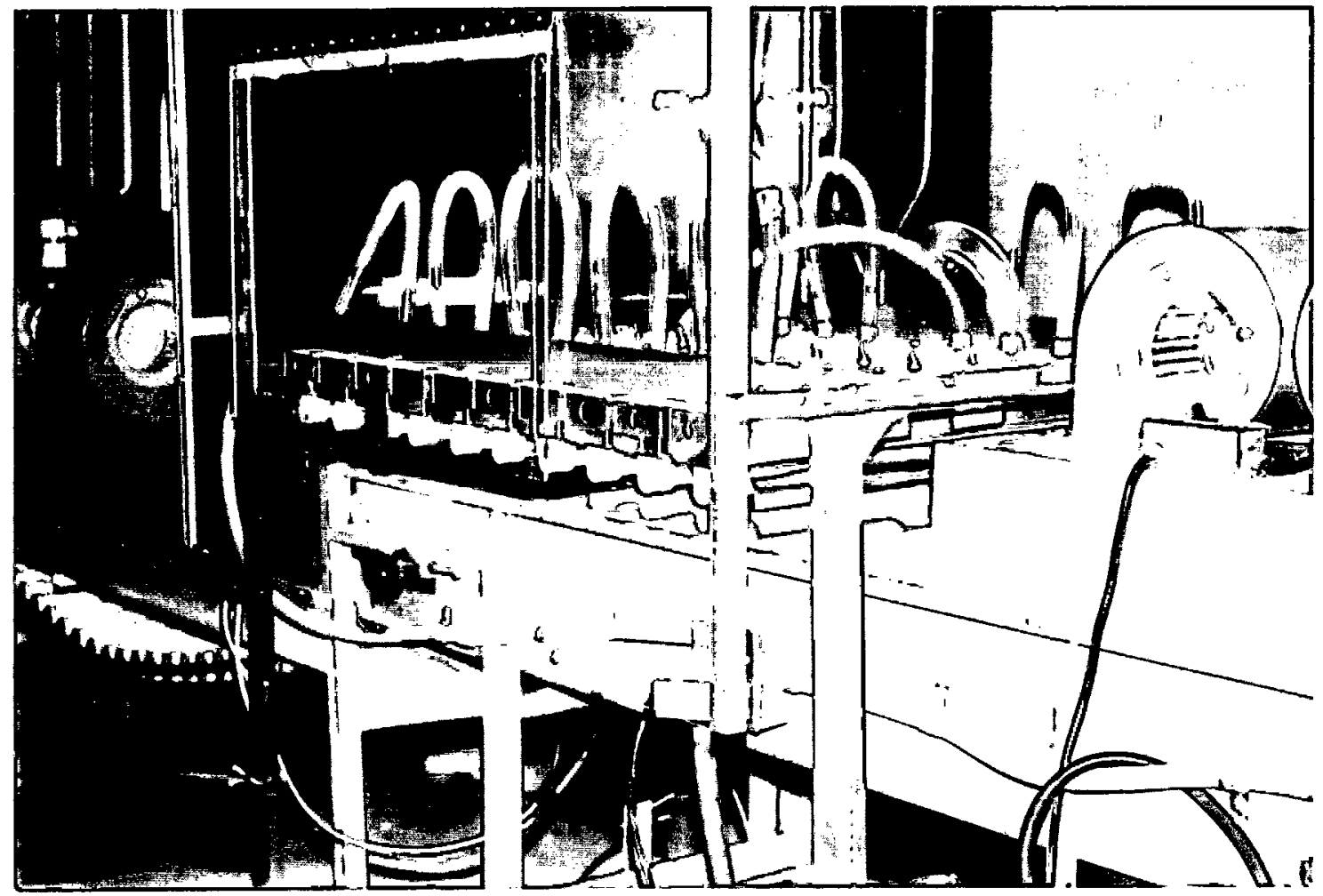

The UV lamps

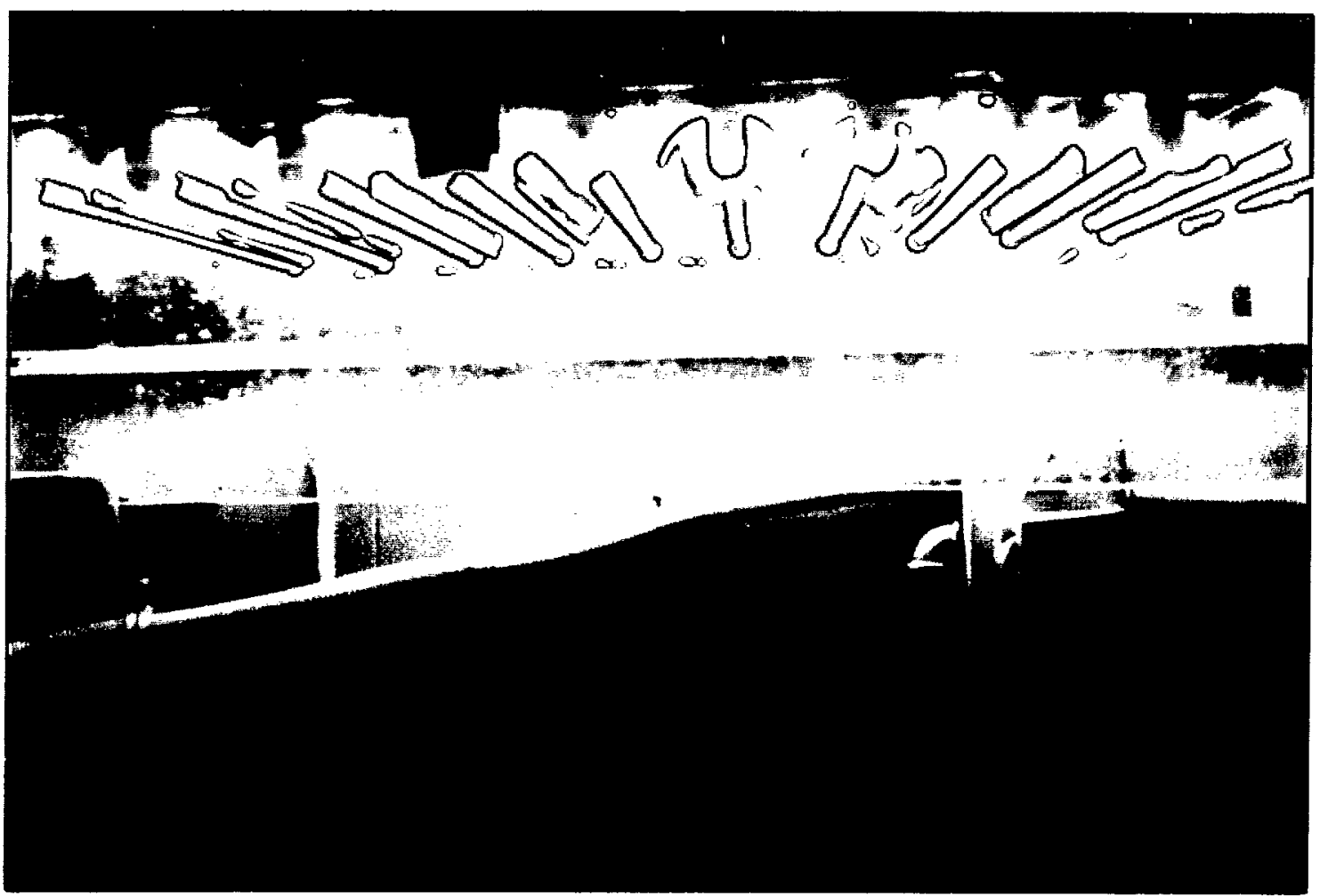


The on line application of the UV treatment in Israel

General view of the pilot line

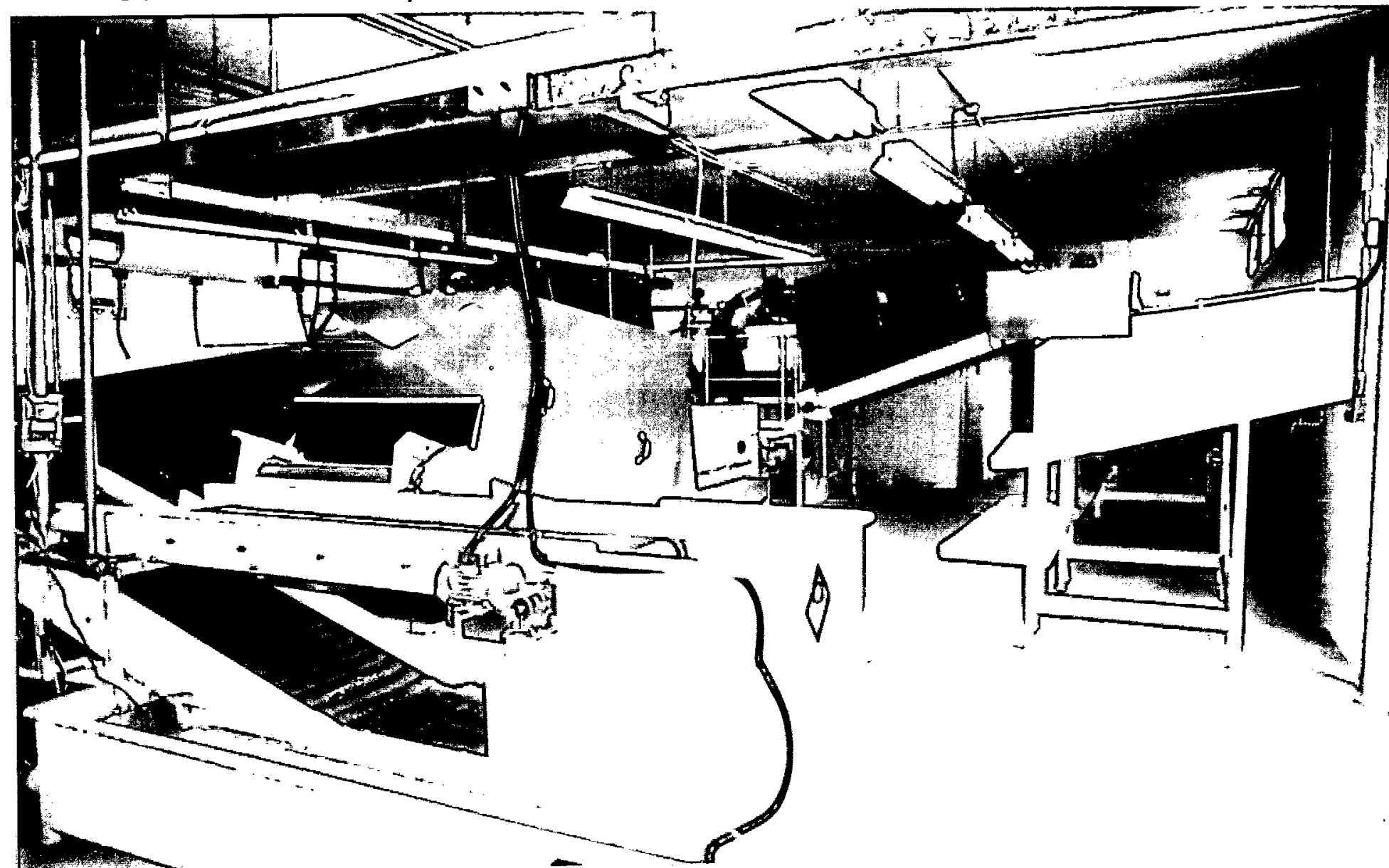

The UV light application system

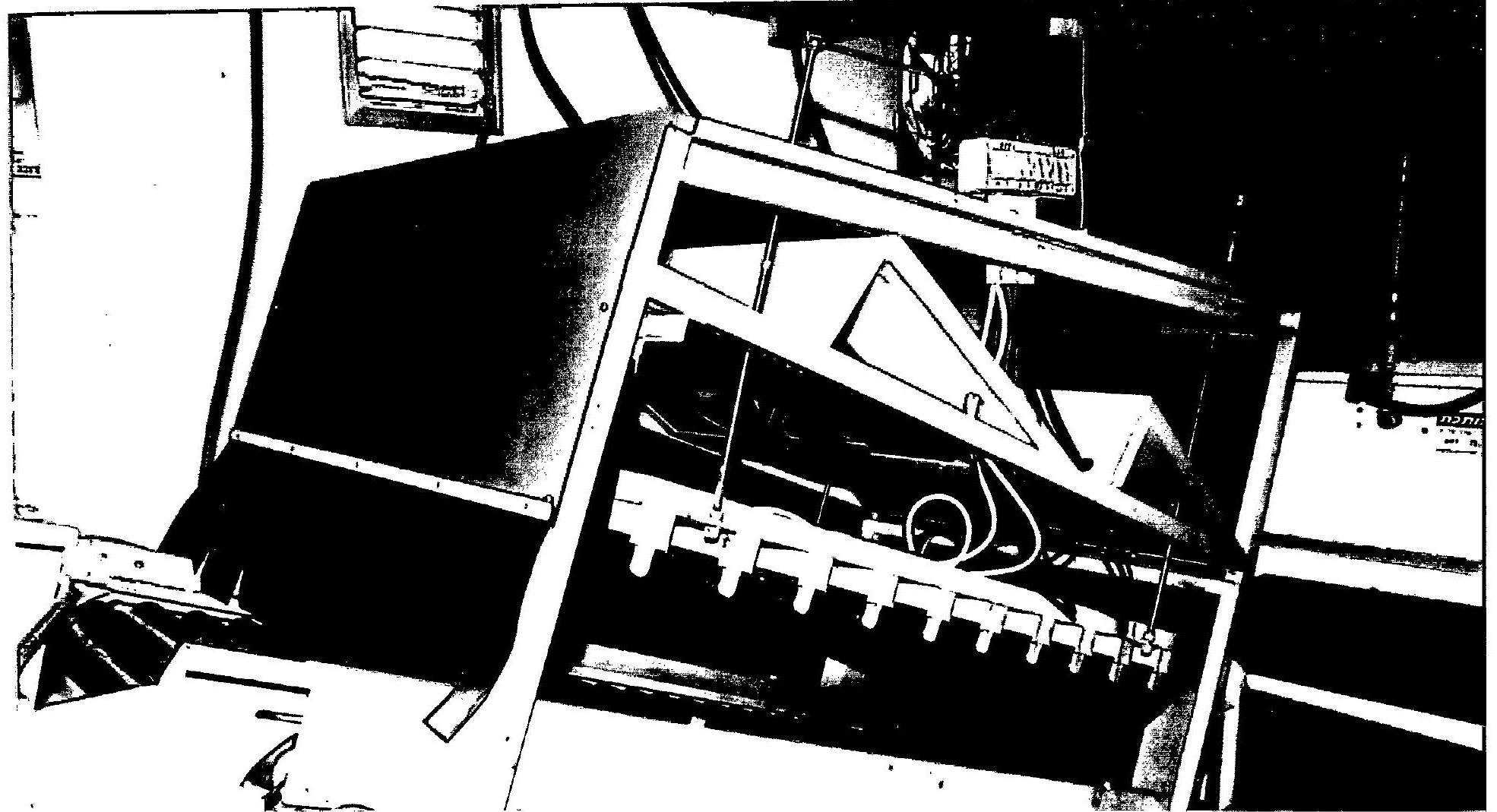




\section{Description of cooperation:}

Close collaboration has characterized the work conducted throughout this research, continuing a several years long tradition of collaboration between the scientists participating in this work. The collaboration took the form of joint planning of experiments, exchange of ideas, new information and materials, as well as mutual visits. In addition, almost all publications have been joint ones.

In addition, the scientists of each of the major collaborating research groups directed their research toward the study of different commodities and research areas. The Israeli group worked mostly on citrus fruit emphasizing photobiological, pathological, biochemical, and molecular aspects. The group in Alabama concentrated on work with sweet potato and other vegetables emphasizing photobiological and physiological responses of the commodity and extension of shelf-life. In West Virginia, deciduous fruits were studied, with emphasize on the various application aspects of the technology.

\section{Evaluation of research achievements}

The research conducted within this project has deepened our knowledge and understanding of the phenomenon of induced resistance to postharvest diseases by UV light. In addition, it has enabled the evaluation of the methodology on a pilot plant scale. Considerable new information has been gathered on biological, physical, and technical aspects of the topic, and problems associated with the application of the methodology have been identified. 


\section{Conclusions}

This research has achieved most of its objectives, although it has not yet resulted in a ready-to-use new method for the control of postharvest diseases of fruits and vegetables. In addition, this project has resulted in the further development of close and fruitful collaboration between scientists in the US and Israel, and the development of new research methods, the purchasing of equipment and the construction of research facilities that will assist in future research. 


\section{List of publications}

(including those originating from a preceding 1-year, BARD-supported feasibility study on the same topic number: IS-1908-90F).

\section{Articles in Review Journals}

1. Chalutz, E., Droby, S., Wilson, C.L. and Wisniewski, M.E. (1992).

UV-induced resistance to postharvest diseases of citrus fruit.

Photochem. Photobiol. B: Biol. 15: 367-374. (included as part of this report).

2. Droby, S., Chalutz, E., Horev, B., Cohen, L., Gaba, V., Wilson, C.L. and Wisniewski, M.E. (1993).

Factors affecting UV-induced resistance in grapefruit against green mold decay caused by Penicillium digitatum.

Plant Pathol. 42: 418-424. (included as part of this report).

3. Liu, J., Stevens, C., Khan, V.A., Lu, J.Y., Wilson, C.L., Adeyeye, O., Kabwe, M.K., Pusey, P.L., Chalutz, E., Sultana, T. and Droby, S. (1993). Application of ultraviolet-C light on storage rots and ripening of tomatoes.

J. Food Prot. 56: 868-872. (included as part of this report).

4. Lu, J.W., Lukombo, S.M., Stevens, C., Khan, V.A., Wilson, C.L., Pusey, P.L. and Chalutz, E. (1993).

Low dose UV gamma radiation on storage rots and physiochemical changes in peaches.

Food Qaul. 16: 301-309. (included as part of this report).

5. Wilson, C.L., El Ghaouth, A., Chalutz, E., Droby, S., Stevens, C., Lu, J.Y., Khan, V. and Arul, J. (1994).

Potential of induced resistance to control postharvest diseases of fruits and vegetables.

Plant Dis. 78: 837-844. (included as part of this report).

6. Stevens, C., Wilson, C.L., Lu, J.Y., Khan, V.A., Chalutz, E., Droby, S., Kabwe, M.K., Haung, Z., Odeyeye, O., Pusey, L.P., Wisniewski, M.E. and West, M. (1996).

Plant hormesis induced by ultraviolet light- $\mathrm{C}$ for controlling postharvest diseases of tree fruits.

Crop Protection 15: 129-134. (included as part of this report).

7. Wilson, C.L., El Ghaouth, A, Upchurch, B., Stevens, C., Kahn, V. A., Droby, S. and Chalutz, E. (1997).

An "on line" UV-C to treat harvested fruit for the control of postharvest diseases.

Hortechnology (accepted, included as part of this report). 
8. Stevens, C., Khan, V.A., Lu, J.Y., Wilson, C.L., Pusey, P.L., Igwegbe, E. C., Kambe, K., Mafolo, Y., Liu, J., Chalutz, E., Droby, S. (1997).

Integration of ultraviolet (UV-C) light with yeast treatment for the control of postharvest storage rots of fruits and vegetables.

Biol. Cont. (accepted, included as part of this report).

9. Stevens, C., Khan, V.A., Lu, J.Y., Wilson, C.L., Pusey, P.L., Kambe, M. K., Igwegbe, E.C.K., Chalutz, E., Droby, S. (1997).

The germicidal and hormetic effects of UV-C light on reducing brown rot disease and yeast microflora of peaches.

Crop Protection (submitted, included as part of this report).

10. Stevens, C., Liu, J., Lu, J.Y., Khan, V.A., Wilson, C.L., Igwegbe, E. C., Kambe, M. K., Chalutz, E., Droby, S. (1997).

Application of hormetic UV-C for delayed ripening and reduction of Rhizopus rot in tomatoes: The effect of tomatine on storage rot development.

J. Phytopathol. (accepted, included as part of this report).

11. Droby, S., Lars, a., Dori, S., Cohen, L., Wiess, B., Daus, A., Chalutz, E., Stevens, C., Wilson, C.L., and El Ghaouth, A. (1977).

Characterization of biochemical changes related to UV-induced resistance against green mold decay in grapefruit peel tissue.

Postharvest Biology \& Technology (to be submitted, included as part of this report).

12. Lars, A., Bord, S., Lomniec E., Droby, S. and Chalutz, E. (1977).

A grapefruit gene encoding an isoflavone reductase-like protein is activated in response to UV irradiation.

Plant Mol. Biol. (to be submitted, included as part of this report).

\section{Other Publications}

13. Droby, S., Chalutz, E., Cohen, L., Wiess, B. and Daus, A. (1991).

Ultraviolet illumination as a means to increase the resistance of citrus fruit against the green-mold fungus Penicillium digitatum.

Alon HaNotea 55: 766-768 (in Hebrew).

14. Stevens, C., Lu, J.W., Kahn, V.A., Wilson, C.L., Chalutz, E. and Droby, S. (1991).

Ultraviolet light induced resistance against postharvest diseases in vegetables and fruits.

Proc. (BARD-Sponsored) Inter. Workshop on Biological Control of Postharvest Diseases of Fruits and Vegetables. Shepherdstown, West Virginia, U.S.A. USDA PUbI. ARS-92: 268-290. 
15. Stevens, C., Lu, J.Y., Khan, V.A., Wilson, C.L., Chalutz, E., Kabwe, M.K., Haung, Z., Adeyeye, O., Pusey, L.P., and Tang, A.Y. (1992).

Induced resistance response of sweetpotato to Fusarium rot by UV-hormesis.

Phytopathol. (prepared presentation, included as part of this report).

16. Chalutz, E. (1994).

Alternatives to chemical fungicides for the control of postharvest diseases of citrus fruit.

Proc. 1994 CLAM Cong. Herzelia, Israel.

17. Lu, J.Y. (1994).

Effect of UV-C irradiation on starch degradation in sweetpotatoes.

Proc. Annu. Mtg. Alabama Fruits and Vegetables Growers Assoc. Nov. 23. Golfshore, Al.

18. Dori, S., Droby, S., Lars, A., Horev, B., Chalutz, E. and Wilson, C.L. (1995). U' $V$-induced resistance in grapefruit against green mold decay caused by Penicillium digitatum.

Proc. Annu. Mtg. of the Israeli Soc. Phytopathol. Bet Dagan, Israel.

19. Liu, J. (1995).

Ultraviolet-C light for delaying ripening and inducing resistance to storage rots of tomatoes.

M.Sc. Thesis. Tuskegee University. (a manuscript summarizing the results is included as part of this report)

20. Wu, B. (1995).

Carbohydrate metabolism UV-C treated sweetpotatoes.

M.Sc. Thesis. Tuskegee University.

21. Stevens, C., Khan, V.A., Lu, J.Y., Wilson, C.L., Pusey, P.L., Kambwe, M.K., Mafolo, Y., Liu, J., Chalutz, E. and Droby, S. (1995).

Reduction of storage rots of fruits and vegetables by combining UV-C application and biocontrol strategies.

Phytopathology 84: 1152-1153 (Abstr.).

22. Jiang, Mengyue, (1966).

The effect of low dose UV-C light and gamma radiation treatments on postharvest storage of Golden Delicious apples.

M.Sc. Thesis. Tuskegee University.

23. Stevens, C., Khan, V.A., Lu, J.Y., Wilson, C.L., El-Ghaouth, A., Chalutz, E., Droby, S. (1997).

Low dose UV-C light as a new approach to control decay of harvested commodities.

In: Recent Research Developments in Plant Pathology, S.G. Pandalai, Ed. Research Signpost (in press, included as part of this report). 


\section{A report on any patents}

No information available. 